\title{
The Effect of Non-Pharmaceutical Methods of Labor Pain Relief on Mothers' Postpartum Depression: A Randomized Controlled Trial
}

\author{
Fahimeh Sehhatie ${ }^{1}$, Mozhgan Mirgafourvand ${ }^{1}$, Zhaleh Vosoughi Niri ${ }^{*}$
}

\begin{abstract}
Objectives: The prevalence of postpartum depression in Iran is about three times of the developed countries. This study is done for investigating the effect of non-pharmacological methods of pain relief in labor on postpartum depression.

Materials and Methods: This is a controlled double-blinded random clinical trial in which 320 referred women were allocated to two intervening group ( 158 women) and control group (162 women) as random blocking. In the intervening group non-pharmacological methods of pain relief in labor was used. Edinburgh questionnaire was used in two stages for assessing depression: first stage before active phase onset, the second phase was eight weeks after delivery. General linear model was used for analyzing data.

Results: Mean (standard deviation) of prenatal depression in the intervening group was 6.1 (3.2) and in the control group it was 6.3 (3.2), which does not show statistically significant difference between the two groups $(\mathrm{P}=0.610)$. Mean (standard deviation) of depression at eight weeks postpartum in the intervening group was 7.9 (4.6) and it was 8.9 (5.4) in the control group.

Conclusion: Having controlled the prenatal depression grades, there was no statistically significant difference between the two groups in postpartum depression. This shows the decrease of depression in the intervening group as compared to the control group which could be due to the effect of non-pharmacological methods of pain relief in labor.

Keywords: Pain, Relief, Labor, Postpartum Depression
\end{abstract}

\section{Introduction}

Pregnancy and labor is a critical stage for women due to its mental pressure. There are ever-increasing evidences which show that the consequences of pregnancy and child's growth are affected by women's mental status in this duration. Mental illnesses affect the relationship of the women with the other family members.

Postpartum depression is one of the mental disorders related to pregnancy and postpartum (1). Postpartum depression is a non-mental depression which occurs during first six weeks after labor and its symptoms are similar to depression symptoms at other times. Depression at first month after labor is three times more than the average monthly occurrence among non-delivered women. Studies in different cultures show that prevalence of postpartum depression among teen mothers is $10-15 \%$ (2). The prevalence of postpartum pregnancy in all the studies ranges from 4.5 to $28 \%$ (3). In domestic studies, the prevalence of postpartum pregnancy is reported at $30 \%$ in North Tehran treatment centers (4), at 34.7\% in Tabriz (5) and at $23.7 \%$ in Qom. The prevalence of postpartum depression in Iran follows the pattern of developing coun- tries which is almost three times of the developed countries (6). In regard to the high prevalence of mental disorders among pregnant women, conducting research for identifying the reasons and developing effective treatment for mental disorders among pregnant women at postpartum stage, is essential (7).

Postpartum depression is defined with mood depression, reduced desire for activity, changing appetite, fatigue, sleep difficulties, difficulty in child care, feeling of guilt, low confidence, difficulty in concentrating, psychomotor pauses, mutability and suicidal thoughts (8). The most prevalent consequences include emotional and behavioral problems and cognitive delay among children of depressed mothers $(9,10)$.

The predisposing factors of depression include mother's young age, smoking, severe vomiting at pregnancy, pregnancy depression, previous depression record, low confidence, physical diseases, weak social support, low social and economic levels, marital problems, unwanted pregnancy, life tragedies, pregnancy and delivery complications, multi-pregnancy, premature birth, and fear of child care (11). 
Most of the studies have reported significant relationship between types of labor with postpartum depression such that the prevalence of postpartum depression among cesarean mothers was more than mothers who had physiologic delivery (12-16). Nowadays, the number of midwifery surgeries and especially cesarean is increasing (17). Danger of maternal morbidity in optional cesarean is increased to 9 times as compared to 3 times in natural vaginal delivery. Meanwhile, maternal morbidity in cesarean delivery is 3 times the vaginal delivery (11).

One of the most prevalent reasons of mothers willingness for cesarean is fear from natural delivery pain (18) and pain control is one of the important parts of modern delivery cares (19). The main aim of care during labor is management of labor pain which is done via pharmacological and non-pharmacological methods. The pharmacological methods are effective in removing the physical feeling of pain, while non-pharmacological methods prevent the pain more efficiently.

Using pharmacological methods in pain relief of labor is considered as a dangerous factor and is usually accompanied by clinical complications and concerns related to each method. On the other hand, the high satisfaction that most women gain from non-pharmacological methods of pain relief in labor show that these methods probably have other benefits which are not known (20). Studies show that supportive and consultative education and actions at pregnancy with reducing the fear of labor has positive effect on the postpartum experience (21). Continuous support of midwife along with observing the principles of natural delivery reduces the intensity of labor pain and its duration remarkably (22) and is effective in prevention from postpartum depression (23). The study by Pilevarzadeh et al. showed that massage reduce pain and anxiety during labor and has positive effect on delivery experience (24). Another study showed that providing postpartum emotional and informatics support considerably reduces the postpartum depression (25).

Regarding the high prevalence of postpartum depression and its undesired complications as well as the benefits of non-pharmacological methods in pain relief of labor and lack of study in this area, the current study was done for determining the effect of non-pharmacological methods of pain relief in labor on postpartum depression among mothers referring to Alavi Training Clinical Center located in Ardebil.

\section{Materials and Methods}

The current study is a random clinical trial that was done in Alavi Training Clinical Center located in Ardebil from Feb. 2012 to Nov. 2012 on 320 women who had the requirements for entering the study. They were randomly allocated in two intervening and control groups. According to the study by Zahraei et al. (25) the sample size of 160 was computed for any group having considered $\alpha=0.05, \beta=0.1$, $\mathrm{M}_{1}=12.6, \mathrm{M}_{2}=10.8, \mathrm{SD}_{1}=4.67, \mathrm{SD}_{2}=4.79$ and $10 \%$ loss.
The criteria for entering the study included a maternal age of 18-35 years old, Iranian nationality, residing in Ardebil province, being literate, a pregnancy age between 38 to 42 weeks, mono-pregnancy, embryo's being natural state, having low risk pregnancy, not taking special and unauthorized drugs, alcohol, smoking during pregnancy, not participating in training classes of physiological delivery during pregnancy, the mother's willingness for participating in research, acquiring grade less than 12 in Edinburg test, not having family depression record, not leaving the parents before 15 years of age, not having previous records of depression and anxiety and stressful life events within the past 6 to 12 months, not having interpersonal violence in past and present, not having infertility record, chronic illnesses and record of thyroid illnesses, hospitalized mothers in potential phase of labor or active phase with 4 $\mathrm{cm}$ dilatation and effacement below or equal to $50 \%$.

The criteria for exiting the study include mother's relinquishment from continuing the intervention and not cooperating or refusing for participating in the research at any stage of study, any need for emergency intervention due to material or embryo reasons such as bleeding resulted from placental abruption, doing emergency cesarean for any reason during labor, trauma during delivery (using delivery tools like forceps or vacuum, wide perineal tear, blooding after deliver, etc.) record of postpartum mother or child being hospitalized, and occurrence of stressful accidents until eight weeks after deliver.

The sequence of random allocation was determined via a computer program by one of the research team members not involved in choosing the samples and for allocation concealment, type of intervention was put in the opaque closed packets which were numbered in order. The qualified persons were allocated into two groups of 160 in intervention and control groups as random blocking method with size of 4 and 6 in blocks and as quota method based on number of deliveries (nulliparous and multiparous).

The available sampling method was first used for sampling, therefore, after the start of the research, having explained the aim of research and acquiring consent, the numbered pockets were opened for determining the type of intervention for the qualified mothers in order of mothers' referring. In this regard, the first pocket was opened for the first qualified person. For other samples, the related pocket was opened respectively and according to the type of intervention, mothers were allocated in one of the two groups.

For bias prevention, the interventions were done frequently in both groups of control and intervention by the first researcher and second researcher assistant. Therefore each of the researcher assistants used the pain relief method in labor once in the intervention group and then performed a traditional delivery.

In the intervention group, with the start of the active phase, establishment of silent setting and observing 
mothers' privacy, non-pharmacological methods of pain relief in labor including showering, being in upright posture, aromatherapy with lavender, and soft music without words were used. For aromatherapy, oily essence produced by Barich Essence, Kashan Company (produced by distillation in $1.5 \%$ density from unopened flowers) was used. The manner of use was as follow: $1 \mathrm{ml}$ solution of $20 \%$ lavender essence (20\% of essence with $80 \%$ distilled water) was impregnated on a $10 \times 10 \mathrm{~cm}$ cloth and attached to the mother's breast with the active phase starts.

In the intervention group, mother's vaginal examination during labor was done in active phase once in every two hours and at the second stage of labor, once in every 30 minutes. Oxytocin and amniotomy was not used for labor progress and labor progress was controlled based on partograph. For preventing from dehydration, mothers were persuaded to use oral fluids. As active phase started, Fetal Heart Rate (FHR) and cervical dilatation was checked for verifying the natural labor progress for 30 minutes and Non Stress Test (NST) was prepared for all mothers and attached to the mothers' files. Having given necessary training by researcher, the mothers were allowed to use hot water with hand shower whenever the felt comfort. All mothers stayed under shower for at least 20 minutes. In this duration, they were under supervision of the researcher. During the shower, the mothers were allowed to stand or sit on the chair as they wished and used swim cap from preventing their hair getting wet. After finishing showering, FHR and cervical dilatation were assessed for assessing the fetal health and labor progress. Then having attached the cloth impregnated with lavender essence and hearing classic relaxing music accompanied with natures sound, the researcher gave the necessary training to mothers for using the labor ball.

At least 30 minutes was considered for doing labor ball exercises. The intervention was as follows: the mothers sat on the labor ball while bending their knees at $90^{\circ}$ and did pelvic movements back or front, right or left, up or below. Despite mothers' ability in keeping their balance on ball, the researcher attended as full-time supporter. Recording of the clinical examination was done at all stages by researcher to prevent bias. In the intervention group, supportive care was given to the mother during labor, delivery and 2 hours after delivery. These supports during labor included continuous attendance behind mother, her emotional and mental support, keeping mother's privacy, caring with respect, giving confidence and Oriflamme, giving correct information on labor progress, assisting in changing the status and putting her in proper positions, supplying the mother's needs and persuading her. The mothers were allowed to use water or filtered liquids if required. At delivery, the researcher continuously attended and gave necessary recommendations on the manner of cooperation during labor, manner of straining during contraction, persuading her to relax between contractions, assuring the mother about the health of the baby and the normal pro- cess of the labor, and calming her.

After delivery, the infant was put on mother's abdomen and having established skin to skin contact and persuading the mother for patting the newborn, they tried to establish the primary connection. After cutting the cord, drying the infant and performing the primary actions, infant was placed in the arms of the mother. The mother was then persuaded to breastfeed her newborn. After removing the placenta, the necessary training and information was given to the mother about child care as well as their own care. Meanwhile during labor, the researcher had no intervention in the labor and acted as supportive by continuous attendance. In the control group, the interventions were customary according to delivery interventions. In the intervention group, there were no cases which required labor induction and augmentation and in both group there were no cases of dystocia during birth. The questionnaires including individual-social particulars and delivery particulars and also Edinburg's questionnaire were used for gathering data. Edinburg's questionnaire has ten items each has 4 choices and according to response, zero to 3 points is allocated for each question. The minimum grade is zero and maximum one is 30 . This questionnaire was prepared by Cox et al. in 1987. It is a suitable tool for screening which can lead to premature recognition of depression symptoms among mothers $(26,27)$. Its Persian copy is a valid and reliable tool for diagnosing postpartum depression and the sensitivity, characteristics and its predictive value is verified $(28,29)$.

Data were analyzed by SPSS ver.13 statistical software. Normality of quantitative data was studied by Skewness and Kurtosis and all had normal distribution. For studying the groups' homogeneity due to individual-social particulars, the Chi-square, process Chi-square, Fisher exact test and $\mathrm{T}$ independent test were used. For comparing the depression grade before intervention among the two groups, the $\mathrm{T}$ independent test and eight weeks later, the ANCOVA test was used upon controlling the grade effect before intervention.

\section{Results}

Data from all randomized women were analyzed by intention to treat. From among 320 mothers who were allocated in groups, 14 were excluded from the study for variety of reasons (husband's death, infant's death, close relative's death, severe family dispute, cesarean, long-time hospitalization of infant, mother's hospitalization after delivery, husband's accident) (Figure 1). Regarding the social-individual particulars, there was no statistically significant difference between the two groups of intervention and control which shows the homology of groups. More than half of the participants in each of the groups (60 and 58\% in the intervention and control groups, respectively) were in the age range of 20-30 years old. Most of mothers in both the groups ( 37.3 and $43.8 \%$ in the intervention and control groups, respectively) had high school certificate, 


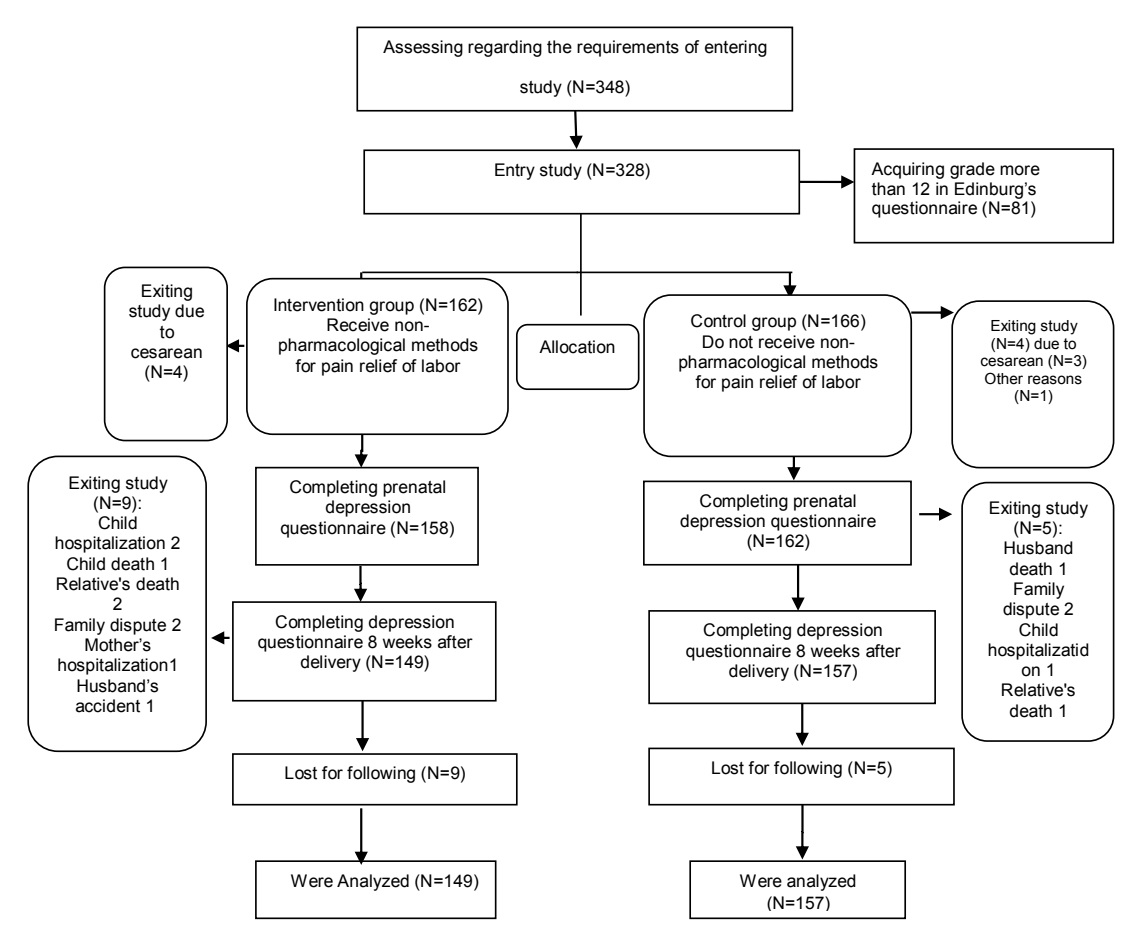

Figure 1. Flow chart of study

and were housewives (94.9 and $97.5 \%$ in the intervention and control groups, respectively). More than half of the mothers in both the two groups (60.8 and $67.3 \%$ in the intervention and control groups, respectively) had medium economic status (Table 1).

Mean (standard deviation) of prenatal depression in the intervention and control groups was 6.1(3.2) and 6.3(3.2), respectively (grade ranged in 0-30) and no statistically significant difference was seen between the two groups $(\mathrm{P}=0.610)$. Mean (standard deviation) of depression grade at eight weeks after delivery in the intervention group and control groups was 7.8 (4.6) and 8.8 (5.4), respectively. Although mean of depression grade in the intervention group (adjusted difference $=0.8,95 \%$ confidence inter$\mathrm{val}=0.2$ to 1.8 ) was less that control group, there was no statistically significant difference between two groups $(\mathrm{P}=0.124)$ (Table 2).

\section{Discussion}

Postpartum depression is a severe impairment which causes the women encounter a very difficult period. Premature recognition, proper and on time treatment is very vital for the health of affected women and their family (30).

The results of current study showed that using non-pharmacological method of pain relief in labor does not lead to significant reduction in mean of postpartum depression eight weeks after delivery, while mean grade among mothers in the intervention group was lower than mothers in the control group. In reviewing the related literature, no similar study was found studying the effect of non-pharmacological methods of pain relief in labor on postpartum depression.
The study done by Ajh et al. in the $3^{\text {rd }}$ trimester of pregnancy on 440 pregnant women showed that supportive actions during pregnancy lead to significant reduction of postpartum depression. These supportive actions were given in three sessions to the mother which included anatomy training, physiology of pregnancy, readiness for delivery, training non-pharmacological method of pain relief in labor, exercises during pregnancy, lamaze exercises, providing educational booklets about postpartum physical and mental care and visiting the delivery room (23). The probable reason of such difference can be related to performing intervention or tools for measuring depression. In the current study, supportive actions and non-pharmacological methods of pain relief during labor and delivery were given.

The results of current study are consistent with that of Hodnett et al. In the study by Hodnett et al. which was done in North American hospitals on 6195 women, the mothers in the intervention group (3454 ones) were supported continuously by the special trained nurse during labor and mothers of control group (3461 ones) received customary care. There was no statistically significant difference between two groups 6-8 weeks after delivery regarding depression (31). Dennis in a reviewing study in 2005 studied 15 trials. These studies were done on 7697 women for evaluating the effect of preventive mental or social mental interventions on postpartum delivery among pregnant or postpartum women less than 6 weeks after delivery. The results showed that psychosocial supports or only psychological supports do not lead to significant reduction in number of women suffering from postpartum depression (32). Meanwhile Dennis in another study 
Table 1. Individual-social and delivery particulars of subjects participating in the groups

\begin{tabular}{|c|c|c|c|}
\hline Particulars & Intervention group ( $\mathrm{N}=158)$ & Control group ( $\mathrm{N}=162$ ) & P-value \\
\hline Age mean ( SD*) & $4.8(24.7)$ & $4.8(24.1)$ & $0.740^{* *}$ \\
\hline Residing place & & & $0.484^{\ddagger}$ \\
\hline Rural & $53(33.5)$ & $61(37.7)$ & \\
\hline Urban & $105(66.5)$ & $101(62.3)$ & \\
\hline Academic status & & & $0.587^{+}$ \\
\hline Elementary & $23(14.6)$ & $25(15.4)$ & \\
\hline Middle & $47(29.7)$ & $48(29.6)$ & \\
\hline High School & $59(37.3)$ & $71(43.8)$ & \\
\hline University & $29(18.4)$ & $18(11.1)$ & \\
\hline Occupation & & & $0.253^{\ddagger}$ \\
\hline Housewife & $150(94.9)$ & $158(97.5)$ & \\
\hline Employed & $8(5.1)$ & $4(2.5)$ & \\
\hline Husband's age mean ( SD*) & $29.4(5.2)$ & $29.2(5.2)$ & $0.996^{* *}$ \\
\hline Family's income sufficiency & & & $0.390^{+}$ \\
\hline Earning more than expense & $46(29.1)$ & $42(25.9)$ & \\
\hline Earning equal to expense & $96(60.8)$ & $109(67.3)$ & \\
\hline Earning less than expense & $16(10.1)$ & $11(6.8)$ & \\
\hline Biomass $\left(\mathrm{kg} / \mathrm{m}^{2}\right)$ mean $\left(\mathrm{SD}^{*}\right)$ & $23.8(3.7)$ & $24.3(4.7)$ & $0.709^{* *}$ \\
\hline Wanting last pregnancy & $142(89.9)$ & $122(82.1)$ & $0.054^{\ddagger}$ \\
\hline Number of pregnancy mean (SD*) & $1(0.8)$ & $1.7(0.9)$ & $0.543^{* *}$ \\
\hline Having abortion record & $20(12.7)$ & $30(18.5)$ & $0.167^{\ddagger}$ \\
\hline Type of delivery & & & $0.858^{\S}$ \\
\hline Vaginal with episiotomy & $104(65.8)$ & $108(67.1)$ & \\
\hline Vaginal without episiotomy & $53(33.5)$ & $53(32.9)$ & \\
\hline Vaginal with $1^{\text {st }} \& 2^{\text {nd }}$ rank tear & $33(60)$ & $26(49.1)$ & $0.493^{\S}$ \\
\hline Placental automated exiting & $157(99.4)$ & 159(98.8) & $1.000^{\ddagger}$ \\
\hline Child's gender & & & $0.655^{\ddagger}$ \\
\hline Boy & $70(44.3)$ & $76(46.9)$ & \\
\hline Girl & $88(55.7)$ & $86(53.1)$ & \\
\hline \multicolumn{4}{|l|}{ Child's Apgar } \\
\hline First minute mean (SD*) & $9(0.1)$ & $8.9(0.6)$ & $0.152^{* *}$ \\
\hline Fifth minute mean (SD*) & $9.9(0.7)$ & $9.9(1.1)$ & $0.400^{* *}$ \\
\hline Weight at birth mean (SD*) & $334.5(325.5)$ & $386.9(325.5)$ & $0.988^{* *}$ \\
\hline $\begin{array}{l}\text { Exclusive feeding of infant by two month } \\
\text { after delivery }\end{array}$ & $145(91.8)$ & $146(91.3)$ & $0.525^{\ddagger}$ \\
\hline
\end{tabular}

All numbers except the defined ones are shown as number (percent).

In the intervention group, there was one case of delivery with equipment.

*Mean(Standard deviation), ${ }^{* *}$ T-test, ${ }^{\ddagger}$ Fisher exact test, ${ }^{\dagger}$ process Chi-square, ${ }^{\S}$ Chi-square

Table 2. Comparing mean of depression grades in intervening and control groups

\begin{tabular}{lllll}
\hline & Variable & $\begin{array}{l}\text { Intervention } \\
\text { mean (SD)* }\end{array}$ & $\begin{array}{l}\text { Control } \\
\text { mean (SD)* }\end{array}$ & $\begin{array}{l}\text { Mean difference } \\
(\mathbf{9 5 \% ~ C l ) * *}\end{array}$ \\
\hline \multirow{2}{*}{ Depression grade (0-30) } & Before intervention & $6.1(3.2)$ & $6.3(3.2)$ & $(-0.2-1.8)-0.8$ \\
& 8 weeks after delivery & $7.8(4.6)$ & $8.8(5.4)$ & 00.124 \\
\hline
\end{tabular}

Data are reported based on general linear model test having adjusted the basic values.

*Mean (standard deviation), ${ }^{* *}$ Mean difference (95\% confidence level)

recognized mothers who are at high risk for postpartum depression via Edinburg's scale and showed that call supporting after delivery leads to high consent and significant reduction of postpartum depression among them (33).

The non-pharmacological methods for labor pain relief used in this study include listening to soft music, using delivery ball, aromatherapy and showering. Several studies were done in this regard. One of these studies which is consistent with the results of this study is the research done by England and Sim which studied the effect of therapeutic methods like aromatherapy, massage therapy, reflexology as supplement treatment on depression; however the documents are unconcluded and needs further studies (34). Meanwhile the result of study by Graham et al. for studying the effect of inhalation aromatherapy during radiotherapy on depression of 313 patients is similar to the current study. In the above research, no significant difference was seen between the two groups of intervention who used pure essence of lavender, bergamot and cedar and control who used placebo regarding depression 
(35). Conrad and Adams showed that aromatherapy leads to significant reduction in postpartum depression. In this study which was done on high-risk women regarding postpartum depression, aromatherapy (combining rose and lavender extract) from 0 to 18 months after delivery in 15 -min sessions, twice a week for 4 continuous weeks was used. The reasons for such difference can be related to duration of using aromatherapy, used extracts and sample size. The above study was a pilot study which was done on 28 high-risk women (36).

In a case study that was done for comparing music therapy with psychotherapy interventions (pharmacological therapy) for depression, results showed that in four out of five studies, there was much reduction in depression symptoms among individuals who were allocated randomly to the intervention group compared to the control group; meanwhile there was no statistical difference in the mental status of intervention group when comparing the music therapy. These results are similar to the current study (37).

In a study by Simavli et al. the effect of music therapy on pain relief during natural delivery and after delivery and mental health of 161 nulliparous mothers was studied. The results showed that postpartum depression among mothers in intervention group (80 women) was significantly less than mothers in control group (81 women) (38). The reason for such difference can be related to time of measuring depression and the type of music listened by the mothers. In the above study depression was measured 1 and 8 days after delivery, while in the current study it was 8 weeks after delivery. Also in the above study the desired music of mothers was used, while in the current study soft music without words (relaxing and classic ones combined with natures' sounds) was listened during labor.

In a study by Chang et al. on 236 pregnant women who were randomly allocated in two groups of music therapy (116 women) and control group (120 women), listening to music for two weeks during pregnancy significantly reduced the postpartum depression among mothers in intervention group (39). Chan et al. did two separate studies in 2009 and 2012 on adult and elderly in Hong Kong and Singapore and showed that using desired music by intervention group leads to significant reduction of depression among people in intervention group $(40,41)$. The considerable and different point of above studies with the current research is using the desired music for a longer duration. Being immersed in hot water during labor and delivery was used for relaxation and pain relief which has long record during clinical cares (42). A group of researchers in Virginia argue that thermal stressful methods can be suitable for treating cancer, chronic fatigue and depression (43). About the effect of using hot water showering on postpartum depression, no study was found. The study by Rush et al. on the effect of bathing in Jacuzzi tub during labor showed that it causes labor pain relief and leads to satisfaction (44). The lack of information on mothers' mental condition when answering the questions was one of the issues that was beyond the control of the researcher.

\section{Conclusion}

The results of this study showed that using non-pharmacological methods of pain relief in labor does not lead to significant reduction in mean grade of postpartum depression and the mean in intervention group is less than the control group. This indicates that such reduction can results from mothers' protection in encountering acute stressful factors and reducing their anxiety during labor by using non-pharmacological methods of pain relief of labor.

\section{Ethical issues}

Ethical issues have observed in this study.

\section{Conflict of interests}

There is not conflict of interests.

\section{Acknowledgments}

This study is derived from Master thesis which was approved under ethics code 91112 on 16/09/2012 by Ethical Council of Tabriz University of Medical Sciences and was recorded under No, 201106143027N7 in IRCT. Hereby the researchers appreciate the cooperation of Research Vice-chancellor of the Faculty of Nursing and Midwifery at Tabriz University of Medical Sciences due to their financial support of this study, the Student Research Committee of Tabriz University of Medical Sciences, the valuable guidelines given by Dr. Abbas Abolghassemi, Associate professor at Department of General Psychology in University of Mohaghegh Ardabili, the Head of Department of Gynecology, all gynecology specialists and residents, midwifery personnel and personnel of delivery room at Alavi Training Clinical Center and also all pregnant mothers who did their utmost in execution of this research.

\section{References}

1. NICE. Antenatal and Postnatal Mental Health: Clinical Management and Service Guidance. NICE clinical guideline 45. Available at www.nice.org.uk/ CG45 [NICE guideline]. 2007, 85;90.

2. Doucet S, Dennis C, Letourneau N, Blackmore ER. Differentiation and clinical implications of postpartum depress and postpartum psychosis. J Obstet Gynecol Neonatal Nurs 2009;38(3):269-79.

3. Scottish Intercollegiate Guidelines Network. Postnatal depression and puerperal psychosis: A national clinical guideline. Edinburgh: 2002.

4. Khooshemehry G, ShariatiFeizabady A, Naserkhaki V, NaserkhakiL. Prevalence of postpartum depression and the factors that decides in clinics in the North of Tehran. Scientific J Hamadan Nursing \& Midwifery Faculty 2011;19(1):59-64.

5. Sehhatie Shafaei F, Ranjbar Koochaksariie F, Ghojazadeh M, Mohamad Rezaei ZH. Study of 
relationship between some predisposing factors and postpartum depression. JAUMS 2008;8(1):54-61.

6. Vesga-lopez O, Blanco C, Keyes K, Olfson M, Grant BF, Hasin DS. Psychiatric disorders in pregnant and postpartum women in the United States. Arch Gen psychiatry 2008;65(7):805-15.

7. Sehhatie Shafaie F, Mirgafourvand M, Rahimi M. Perceived Stress and its Social-Individual Predicors among Infertile Couples Referring to Infertility Center of Alzahra Hospital in Tabriz in 2013. International Journal of Women's Health and Reproduction Sciences 2014; 2: 291-296.

8. Ryan KJ, Berkowitz RS, Barbieri RL, Dunaif AE. Kistner's gynecology and women's health. Translated by Ghazi Jahani B, Ghotbi R. Tehran: Andisheye Roshan; 2001. Persian.

9. Murray L, Sinclair D, Cooper P, Ducournau P, Turner P. The socioemotional development of 5-year-old children of postnatally depressed mothers. J Child Psychol Psychiatry 1999;40(8):1259-71.

10. Sinclair D, Murray L. Effects of postnatal depression on children's adjustment to school. Br J Psychiatry 1998;172:58-63.

11. Canningham FG, Leveno KJ, Bloom SL, Hauth JC, Rouse DC, Spong CY. Williams obstetrics, 23rd ed. New York: Mc Grow Hill; 2010.

12. Farzad M, Ghazi Mir Saeed S. [Association between type of delivery and maternal blue]. Pejouhesh 2005;29(4):331-5. Persian.

13. Doulatian M, Maziar P, Alavimajd H, Yazdjerdi M. The relationship between mode of delivery and postpartum depression. J Reprod Infertil 2006;7(3):260-8.

14. Abedian Z, Nikpour M, Mokhber N, Ebrahimi S, Khani S. Evaluation of relationship between delivery mode and postpartum quality of life. Iranian J Obstet Gynecol Infertil 2010;13(3):47-53.

15. Torkan B, Parsay S, Lamyian M, Kazemnejad A, Montazeri A. Postnatal quality of life in women after normal vaginal delivery and cesarian section. BMC Pregnancy Childbirth 2009;9:4.

16. Bland MA. The effects of birth experience on postpartum depression. Available from http:// clearhouse.missouriwestern.edu/manuscripts/59. php. Accessed 10 Jan 2012.

17. Khosravi A, Najafi F, Rahbar M, Motlagh ME, Kabir MJ. [Health indicators in the Islamic Republic of Iran]. Ministery of Health and Medical Education; 2010. Persian.

18. Nakhostin-Roohi P, Abbasgholizadeh K, Mahmoodi $\mathrm{M}$. Investigate the causes of cesarean section in the first half of 1380 in Alavi hospital in Ardabil. Available from: http://lib.arums.ac.ir

19. Gibbs RS, Karlan BY, Haney AF, Nygaard IE. Dan forth's Obstetrics and Gynecology. 10th ed. Translated by Voldan M, Boozari B, Razzaghi S, Jalili A, Nazem S. Tehran: Arjmand; 2009. Persian.

20. Simkin PT, Klein MC. Nonpharmacologic approaches to management of labor pain. [Cited on $2007 \mathrm{Nov}$ 28]. Available from: http://www.update.com

21. Waldenström U, Hildingsson I, Ryding EL. Antenatal fear of childbirth and its association with subsequent caesarean section and experience of childbirth. BJOG 2006;113(6):638-46.

22. Ahmadi Z. Evaluation of the effect of continuous midwifery support on pain intensity in labor and delivery. J Rafsanjan Univ Med Sci 2010;9(4):293-304.

23. Ajh N, Unesian M, Fili A, Abasi Motejaded A. The study of supportive activities during pregnancy on postpartum depression. Hayat 2006;12(3):73-80.

24. Pilevarzadeh M, Salari S, Shafiee N. Effects of massage on pain and anxiety during labour. J Reprod Infertil 2002;3(4):42-6.

25. Hassan Zahraee R, Fahami F, Yazdani M, Ahmadi Z, Bashardoost N. Supportive role of the midwife in preventing postpartum depression. J Qazvin Univ Med Sci 2003;7(1):19-24.

26. Cox JL, Holden JM, Sagovsky R. Detection of postnatal depression. Development of the 10-item Edinburgh Postnatal Depression Scale. Br J Psychiatry 1987;150:782-6.

27. Cox J, Holden JE. Perinatal psychiatry: use and misuse of the Edinburgh Postnatal Depression Scale. London: Gaskell; 1994.

28. Mazhari S, Nakhaee N. Validation of the Edinburgh Postnatal Depression Scale in an Iranian sample. Arch Womens Ment Health 2007;10(6):293-7.

29. Montazeri A, Torkan B, Omidvari S. The Edinburgh Postnatal Depression Scale (EPDS): translation and validation study of the Iranian version. BMC Psychiatry 2007;7:11.

30. Doucet S, Dennis CL, Letourneau N, Blackmore ER. Differentiation and clinical implications of postpartum depression and postpartum psychosis. J Obstet Gynecol Neonatal Nurs 2009;38(3): 269-279.

31. Hodnett ED, Lowe NK, Hannah ME, Willan AR, Stevens B, Weston JA, et al. Effectiveness of nurses as providers of birth labor support in North American hospitals: a randomized controlled trial. JAMA 2002;288(11):1373-81.

32. Dennis CL. Psychosocial and psychological interventions for prevention of postnatal depression: systematic review. BMJ 2005;331(7507):15.

33. Dennis CL. The effect of peer support on postpartum depression: a pilot randomized controlled trial. Can J Psychiatry 2003;48(2):115-24.

34. Sim LJ, England MJ. Treatment of depression in parents. In: National Research Council and Institute of Medicine. Depression in parents, parenting, and children: opportunities to improve identification, treatment, and prevention. Washington, D.C.: The National Academic Press; 2009. Available from: http://www.nap.edu/catalog.php?record_id=12565

35. Graham PH, Browne L, Cox H, Graham J. Inhalation aromatherapy during radiotherapy: results of a placebo-controlled double-blind randomized trial. J 
Clin Oncol 2003;21(12):2372-6.

36. Conrad P, Adams C. The effects of clinical aromatherapy for anxiety and depression in the high risk postpartum woman - a pilot study. Complement Ther Clin Pract 2012;18(3):164-8.

37. Maratos AS, Gold C, Wang X, Crawford MJ. Music therapy for depression. Cochrane Database Syst Rev 2008;23;(1):CD004517.

38. Simavli S, Kaygusuz I, Gumus I, Usluogulları B, Yildirim M, Kafali H. Effect of music therapy during vaginal delivery on postpartum pain relief and mental health. J Affect Disord 2014; 156:194-9.

39. Chang MY, Chen $\mathrm{CH}$, Huang KF. Effects of music therapy on psychological health of women during pregnancy. J ClinNurs 2008;17(19):2580-7.

40. Chan MF, Wong ZY, Onishi H, Thayala NV. Effects of music on depression in older people: a randomised controlled trial. J ClinNurs 2012;21(5-6):776-83.

41. Chan MF, Chan EA, Mok E, Kwan Tse FY. Effect of music on depression levels and physiological responses in community-based older adults. Int J Ment Health Nurs 2009; 18(4):285-94.

42. Calvert I. The evaluation of the use of herbal substances in the bath water of labouring women. Personal communication 2000.

43. Shevchuk NA, Radoja S. Possible stimulation of anti-tumor immunity using repeated cold stress: a Hypothesis. Infect Agent Cancer 2007;2:20.

44. Rush J, Burlock S, Lambert K, Loosley-Millman M, Hutchison B, Enkin M. The effects of whirlpools baths in labor: a randomized, controlled trial. Birth 1996;23(3):136-43. 